\title{
Design methodology of smart photovoltaic plant
}

\author{
Boutlilis Fatima $^{1}$, Chouitek Mama ${ }^{2}$, Bekkouche Benaissa ${ }^{3}$ \\ ${ }^{1,3}$ Department of Electrical Engineering, Signals and Systems Laboratory Research, Faculty of Science and Technology, \\ Abdelhamid Ibn Badis University, Mostaganem, Algeria \\ ${ }^{2}$ Institute of Maintenance and Industrial Security of University A.B of Oran, Algeria
}

\begin{tabular}{|c|c|}
\hline Article Info & ABSTRACT \\
\hline Article history: & In this article, we present a new methodology to design an intelligent \\
\hline Received May 17, 2020 & $\begin{array}{l}\text { photovoltaic power plant connected to an electrical grid with storage to } \\
\text { supply the laving hen rearing centers. This study requires a very competent }\end{array}$ \\
\hline Revised May 21, 2021 & design methodology in order to optimize the production and consumption of \\
\hline Accepted Jun 14, 2021 & $\begin{array}{l}\text { electrical energy. Our contribution consists in proposing a robust } \\
\text { dimensioning synthesis elaborated according to a data flow chart. To achieve }\end{array}$ \\
\hline Keywords: & $\begin{array}{l}\text { this objective, the photovoltaic system was first designed using a } \\
\text { deterministic method, then the software "Homer" was used to check the }\end{array}$ \\
\hline Design & feasibility of the design. Then, controllers (fuzzy logic) were used to \\
\hline Fuzzy logic & optimize the energy produced and consumed. The power produced by the \\
\hline Internal climate livestock & extract the maximum energy and another to control the batteries. The energy \\
\hline buildings & consumed by the load is optimized by a fuzzy controller that regulates the \\
\hline Photovoltaic & internal climate of the livestock buildings. The proposed control strategies \\
\hline Storage & are developed and implemented using MATLAB/Simulink. \\
\hline
\end{tabular}

This is an open access article under the CC BY-SA license.

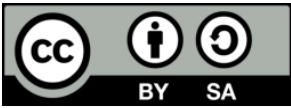

Corresponding Author:

Boutlilis Fatima

Department of Electrical Engineering

Faculty of Science and Technology

Abdelhamid Ibn Badis University

Mostaganem, Algeria

Email: boutlifatima@gmail.com

\section{INTRODUCTION}

To solve the global warming potential and depletion of fossil fuels, the Paris agreement was adopted through the $21^{\text {st }}$ conference held in Paris, France in December 2015. In response to this, the Algerian government plans to launch several projects by 2020, with a total capacity of $800 \mathrm{MW}$. During the period 2021-2030, PV plants of 200 MW per year are expected to be built [1].

The production of electricity with a photovoltaic system connected to the grid is of great interest to countries with high solar potential. However, the design of such a system must be taken correctly in order to optimize the collection of radiation by the photovoltaic cells and increase the efficiency of the system. The use of smart technology can improve the operation of these plants. Therefore, it helps to improve the quality of service of the electricity network, which has been insufficient in recent years, due to the great demand on electricity. In summary, this work concerns the design and optimization of the operation of a smart photovoltaic generator used to supply an industrial campus for laying hens, located in western Algeria. These sites were created in the 1990s by the Algerian government to improve poultry production [2]. It contains four centers, two for the preparation (breeding) of the laying hen and two laying centers. Each center is made up of 10 livestock buildings with an area of $80 \times 12 \mathrm{~m}^{2}$, i.e. 40 buildings for the entire site. Each building is equipped with an electrical control cabinet. To better undertake this study, a survey was launched on the 
requirements of the company, the conditions of the site to design the photovoltaic system and to understand the techniques of raising laying hens. However, we concluded that such a project requires a very competent design methodology in order to optimize the production and consumption of electrical energy and thus reduce investment costs. Therefore, we have proposed a robust dimensioning of the photovoltaic system as shown in the flowchart in Figure 1. It contains three steps. First for the dimensioning we used a deterministic approach based on the worst month of the year [3]. To validate the design results and determine the optimal configuration, the Homer design software [4] was integrated in the second phase of this work. Indeed, the interpretation of the HOMER results allowed us to validate the sizing steps carried out previously and to have an optimal configuration of the system in order to ensure the best compromise between technical feasibility and economic profitability. The third design phase was devoted to the optimization of the energy produced and consumed.

However, to optimize the energy produced, we have proposed the use of a fuzzy intelligent regulator to extract the maximum MPPT power [5] and, another fuzzy regulator to charge and discharge the batteries because this device is very sensitive in these installations. In addition, the building must create an environment favorable to the breeding of poultry, that is to say meeting their physiological needs. These requirements are determined by temperature, air speed and humidity [6], [7]. It therefore influences the profile of electrical energy consumption and the equipment operating service. To optimize the energy consumed, we used intelligent temperature and humidity controllers. These controllers are very effective and robust in maintaining the internal climate according to the standards required for raising chickens. The MATLAB/Simulink software was used for the simulation of all the intelligent control procedures [8].

\section{RESEARCH METHOD}

\subsection{Design methodology}

In general, the design methodology of a photovoltaic system is based on standard approaches [9]-[11]. However, each designer has to design his own algorithm that depends on the nature of the system to be sized, the functional relationships between the system components, the external influences and the technology used. Our design methodology is summarized in the flowchart shown in Figure 1.

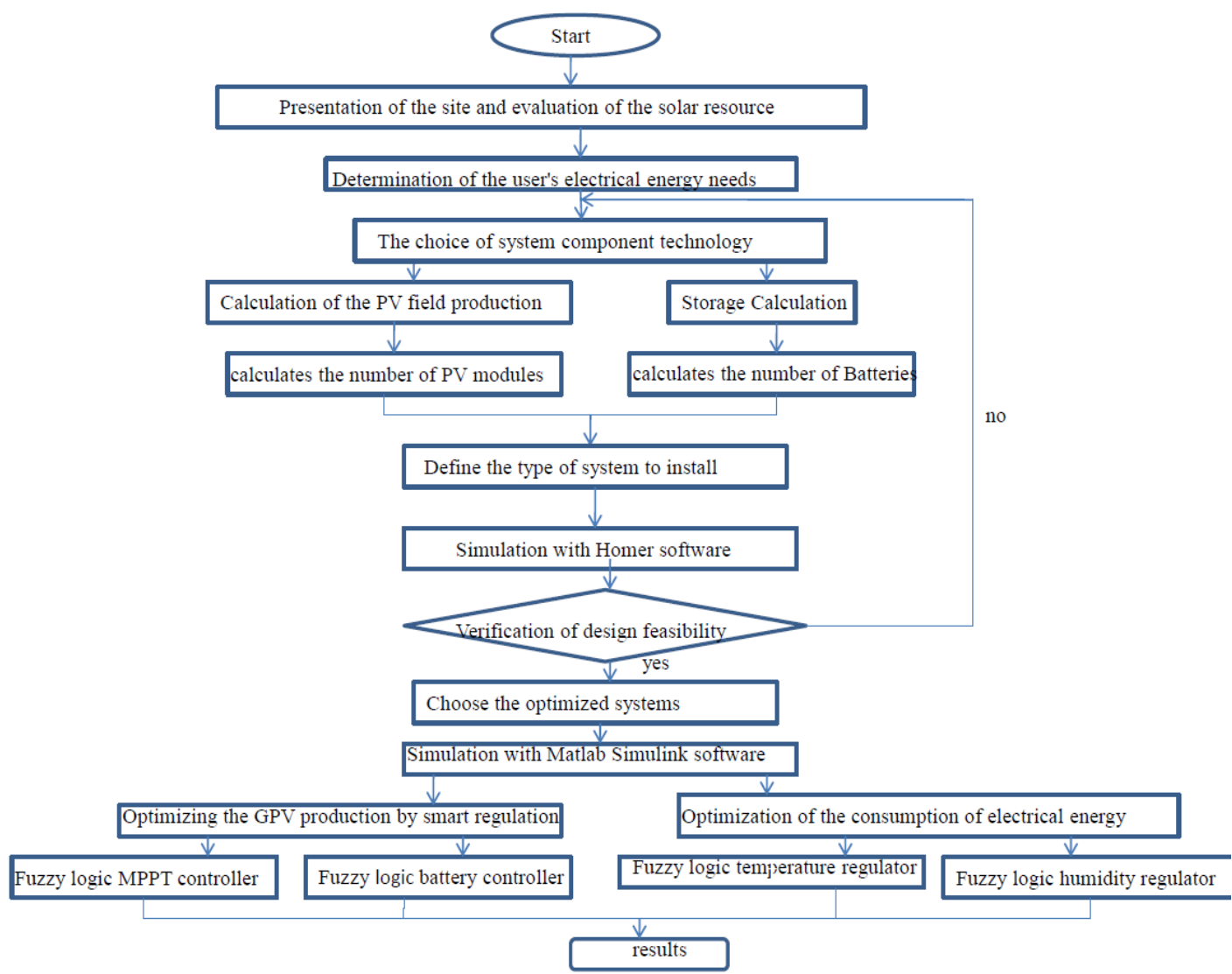

Figure 1. The flowchart of our methodology 
This structure includes the following main phases:

First phase: classic dimensioning;

Second phase: verification of the feasibility of the design with the "Homer" design software;

Third phase:

a. Optimization of the production of the photovoltaic system;

b. Optimization of electrical energy consumption by intelligent control of the interior climate of the livestock building

\subsection{Details of the various phases}

\subsubsection{First phase: classic sizing}

a. Presentation of the site and evaluation of the solar resource

Geographical coordinates of the breeding site Latitude: 35 degrees 12 minutes north, Longitude: 1 degree 15 minutes East, Time: GMT +1: 00. The ideal orientation of a photovoltaic panel obeys the rule of orienting it towards the equator. Since latitude of our installation is $\left(35^{\circ}\right)$, the inclination will be $\alpha=35+10=45^{\circ}$.

b. Meteorological data

For this study, technical data is collected from the NASA global satellite [11]. It should be noted that the average monthly solar radiation in the region exceeded $7.14 \mathrm{kWh} / \mathrm{m}^{2} /$ day in June and decreased to $2.25 \mathrm{kWh} / \mathrm{m}^{2} /$ day in December with an average of $4.72 \mathrm{kWh} / \mathrm{m}^{2} /$ day. Therefore, the most unfavourable month was taken into account in the design procedure [12], [13].

c. The determination of the user's electrical energy needs

However, the electrical energy E consumed by the breeding center is calculated by (1).

$$
E_{t}=\sum_{i=1}^{n} P_{i} t_{i}
$$

With: $\mathrm{P}_{\mathrm{i}}=$ electrical power of a device expressed in Watt $(\mathrm{W})$,

$\mathrm{t}_{\mathrm{i}}=$ duration of use of this device in hours per day $(\mathrm{h} / \mathrm{d})$

The peak power of the panels of two buildings is obtained by:

$$
\mathrm{E}_{\text {zone }}=\mathrm{N}_{\mathrm{e}} * \mathrm{P}_{\mathrm{c}} * \mathrm{C}_{\mathrm{P}}
$$

$\mathrm{E}_{\text {zone }}(\mathrm{kWh} / \mathrm{d})=$ the energy consumed

$\mathrm{Ne}=2.25 \mathrm{~h}$ : the period of solar irradiation of the worst month (December)

$\mathrm{Cp}=0.6$ : the equivalent coefficient of losses inherent in the whole process of energy conversion.

d. Dimensioning of electrical energy storage

The objective of the sizing of the Battery Park is to have a good yield, a long life and a low investment cost [14]. In general, the main characteristics of an accumulator are:

- The voltage at the terminals of an accumulator element;

- The capacity provided by the manufacturers for a given discharge regime in hours (C20 or C100);

- The discharge depth Pd which represents the maximum discharge threshold.

The calculation of the usable and nominal capacity:

$C_{U}$ : Useful capacity of the battery in $W h$,

Nja: Number of days of autonomy without solar input (02 Days)

$E_{\text {zone }}$ : Daily consumption of the zone in Wh/day

$R t$ : Temperature coefficient

The calculation of nominal capacity $C_{n o m}$ is given by

$$
\mathrm{C}_{\text {nom }}=\frac{\mathrm{N}_{\mathrm{ja}} * \mathrm{E}_{\mathrm{zone}}}{\text { Pd x Rt }}
$$

e. Define the type of system to install

The chosen configuration includes a photovoltaic generator with MPPT controller, a storage system with battery regulators, DC/DC converters, DC/AC converters, load and power grid as shown in Figure 2, [15], [16]. 


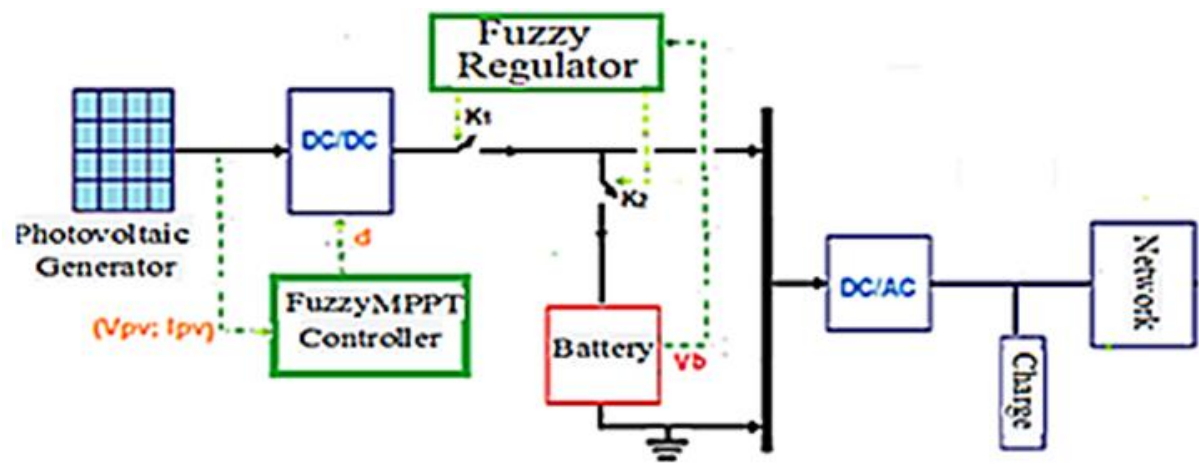

Figure 2. Scheme of the proposed photovoltaic system

\subsubsection{Second phase: verification of design feasibility with "homer" design software}

The designed system is introduced into the software by specifying the options of technology availability, component cost and resource availability. HOMER is a simulation and technical and economic optimization software for hybrid renewable energy systems. The method used by Homer gives us the reliability of the system by loss of power supply probability (LPSP) which is calculated for each configuration and the optimal configuration chosen is based on the minimum life cycle cost (LCC). The architecture of the photovoltaic power plant using the Homer interface is illustrated in Figure 3. Therefore, our main objective is to evaluate the feasibility of the studied PV system [17], [18].

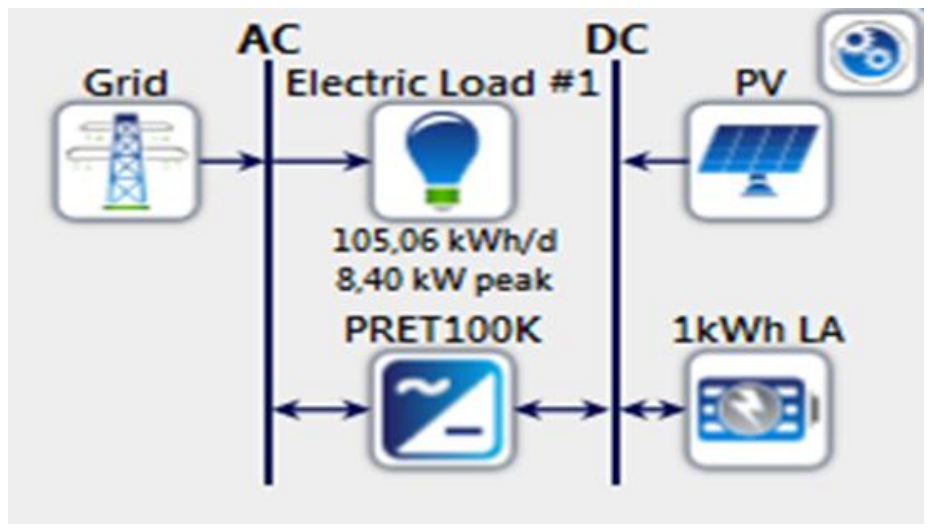

Figure 3. Architecture of the PV plant

a. How to use [18]

Place the site on the geographic map of the software to identify the coordinates. Assemble the components and choose their technical characteristics. Introduce or import the average consumption of the load per hour for each month of the year.

\subsubsection{Third phase: Optimization of the energy produced and consumed by intelligent controllers}

In short, fuzzy theory allows "the rigorous modeling and processing of imprecise, uncertain and subjective information". It allows the approximation of non-linear functions. It is therefore a theory that is perfectly adapted to the optimization problem we are dealing with in this work [19], [20].

a. Optimizing the GPV production by smart regulation

In this phase, we propose two fuzzy regulators. An intelligent MPPT controller will be used to extract the maximum power produced by the photovoltaic generator. Another fuzzy regulator will be used to control the charge and discharge of the battery. At the end, a check of the GPV generator operation will be performed to confirm the optimization phase of the energy production. The simulation is performed with MATLAB/Simulink [21], [22]. Figure 4 shows the proposed global system model. 


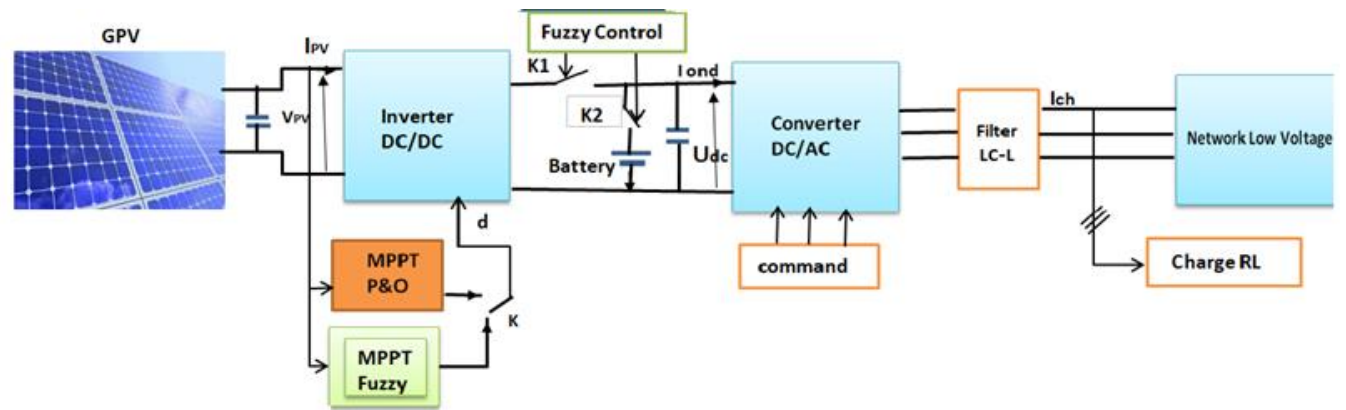

Figure 4. The proposed overall system model

1) Fuzzy MPPT controller

To determine the efficiency and transient response times of the fuzzy MPPT controller. The latter has been compared to a widely used conventional P\&O controller [23], [24]. To implement the fuzzy controller, we need two inputs $\left\{\left(\frac{d P}{d V}\right)\right.$ and $\left.\left(\frac{d^{2} P}{d V^{2}}\right)\right\}$. The output is the change in the duty cycle $\Delta \mathrm{d}$ of the DC/DC converter. This value is used to determine the $\mathrm{V}_{\text {MPPT }}$ value at any time. Figure 5 shows the configuration of the selected fuzzy controller with these three phases.

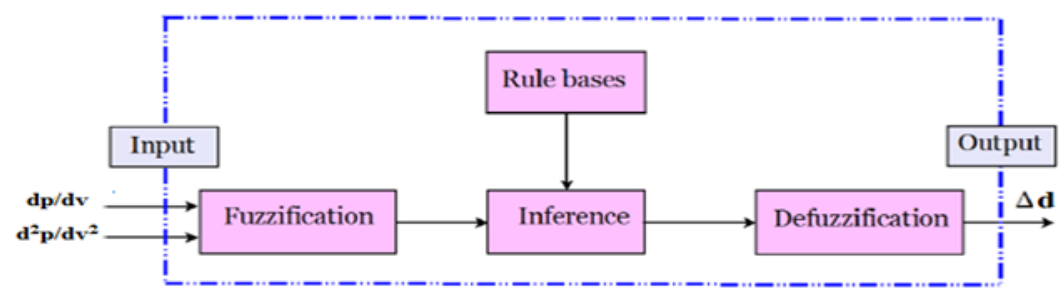

Figure 5. The proposed MPPT control using fuzzy logic

After obtaining the value of the output $\Delta \mathrm{d}$ at time $\mathrm{k}$ we calculate the new duty cycle and apply it to the DC/DC converter:

$d(k)=d(k-1)+\Delta d(k)$

Each fuzzy inputs and output variables are divided into five fuzzy sets, viz. negative big (NB), negative small (NS), zero (Z), positive small (PS), and positive big (PB). Figures 6 and 7 show its membership functions of fuzzy input and output variables, respectively. The control rules for this FLC controller is shown in Table 1.

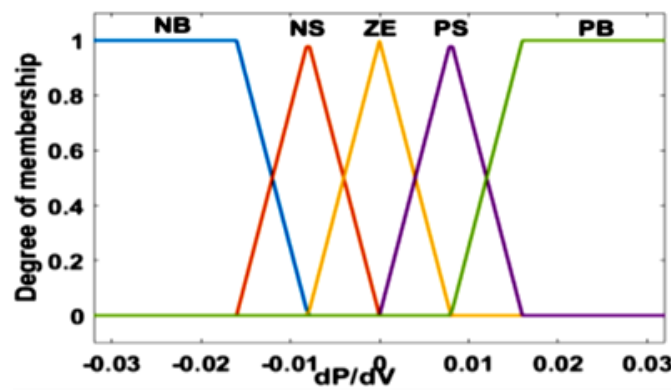

(a)

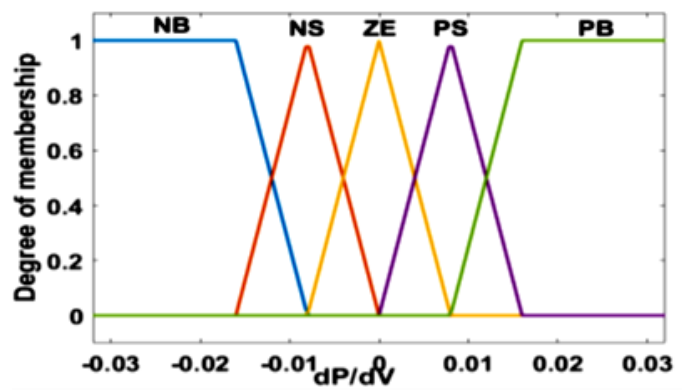

(b)

Figure 6. Membership functions of fuzzy input: (a) $\frac{d P}{d V}$, (b) $\frac{d^{2} P}{d V^{2}}$ 


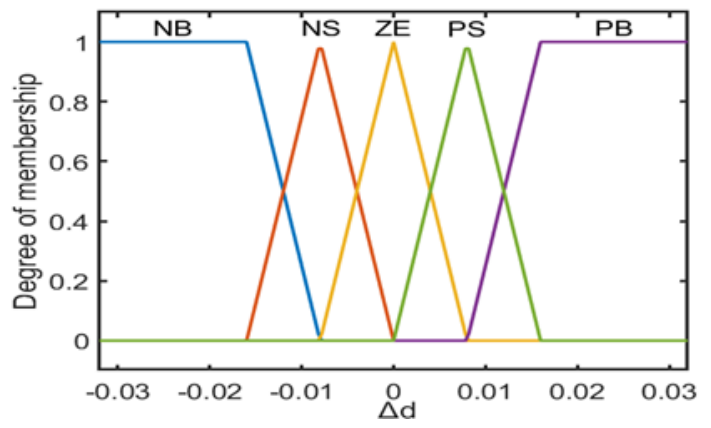

Figure 7. Membership functions of fuzzy output

Table 1. Rule base for the fuzzy ouput variable

\begin{tabular}{|c|c|c|c|c|c|c|}
\hline \multirow{3}{*}{$\Delta$} & & \multicolumn{5}{|c|}{$d^{2} P$} \\
\hline & & & & $\frac{d V^{2}}{2}$ & & \\
\hline & & NB & NS & ZE & PS & PB \\
\hline \multirow{5}{*}{$d P / d V$} & NB & $\mathrm{ZE}$ & $\mathrm{ZE}$ & PB & PB & PB \\
\hline & NS & ZE & ZE & PS & PS & PS \\
\hline & $\mathrm{ZE}$ & PS & $\mathrm{ZE}$ & ZE & $\mathrm{ZE}$ & NS \\
\hline & PS & NS & NS & NS & $\mathrm{ZE}$ & $\mathrm{ZE}$ \\
\hline & PB & NB & NB & NB & $\mathrm{ZE}$ & ZE \\
\hline
\end{tabular}

2) Fuzzy charger battery

For the control of the battery charge and discharge regulator, a fuzzy model of Takagi-Sugeno [25], [26] has been chosen, which presents an efficient technique. The input is the battery voltage (Vb) and the outputs are the signals $\mathrm{K} 1$ and $\mathrm{K} 2$. The signal (K1) is the command of switch 1 between the GPV and the battery $[0,1]$ and the signal (K2) is the command of switch 2 between the battery and the load $[0,1]$ as shown in Figure 8(a) and 8(b) [13].

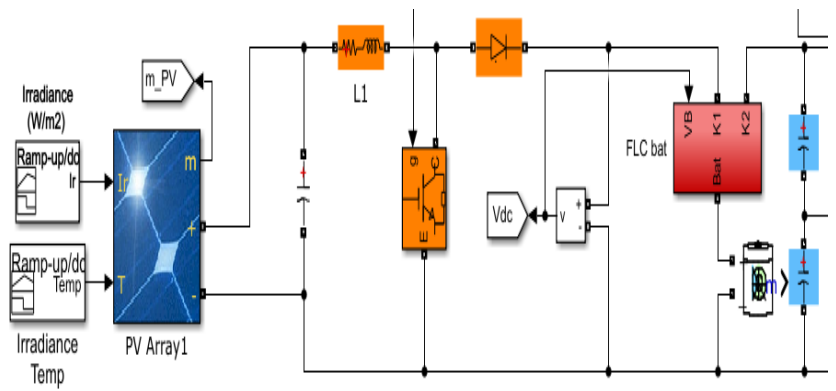

(a)

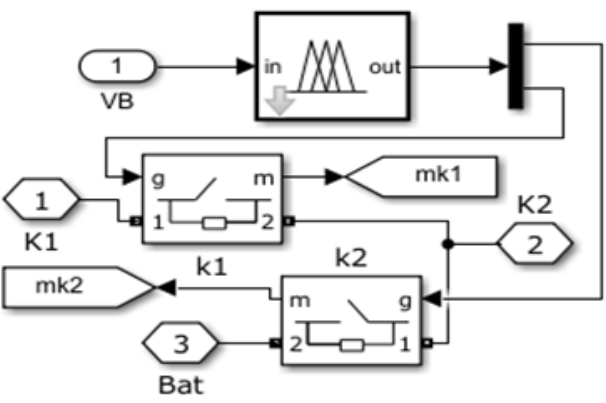

(b)

Figure 8. Fuzzy charger battery; (a) schema of charging and discharging the battery, (b) the fuzzy battery regulator model

b. Verification of the operation of the GPV generator

After confirming the robustness of the two previous controllers, we tested the operation of the GPV.

1) Optimization of the consumption of electrical energy

When the internal climate of the building is unstable, this has a great influence on the life of the hens with consequences on the consumption of electrical energy. However, to stabilize the internal climate and reduce the operating time of the equipment, thus saving energy [27], [28]. We equipped the building with two fuzzy logic controllers, temperature and humidity. The temperature controller model has two inputs, a temperature error (Tref-Ti) and external temperature $\mathrm{T}_{0}$. Thus, it contains two outputs, to control heating and ventilation as shown in Figure 9(a). The humidity controller model has two inputs, humidity error (Href-Hi) and outdoor humidity $\mathrm{H}_{0}$, as well as an output for controlling the humidifier as shown in Figure 9(b). 


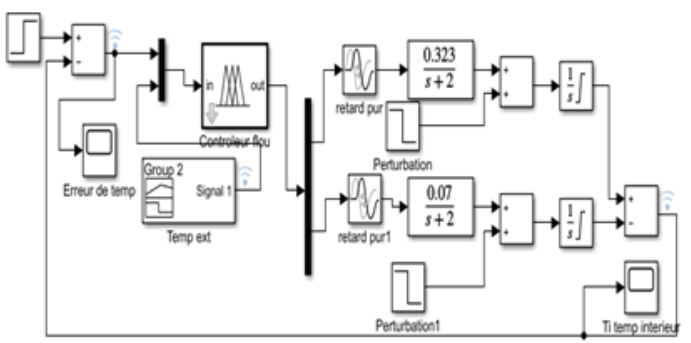

(a)

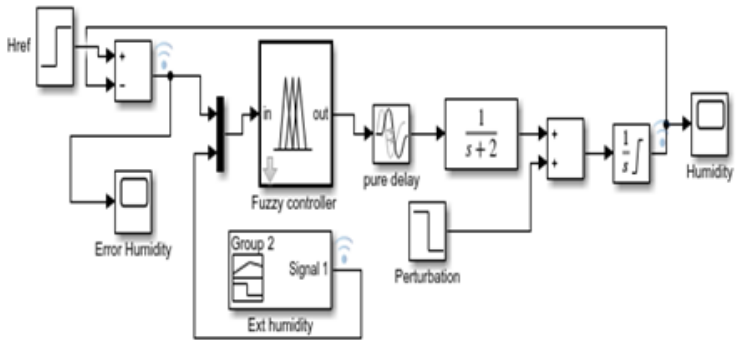

(b)

Figure 9. Fuzzy logic controllers (a) The temperature controller, (b) The humidity controller

\section{RESULTS}

\subsection{The results of the first phase}

The results of the calculations of the first phase of the photovoltaic installation are summarized in Table 2. The results obtained show that the generator works correctly to meet the load demanded by the campus, because we based our calculations on the sunshine of the most devourable month.

Table 2. The dimensions of the photovoltaic power plant designed

\begin{tabular}{cc}
\hline Parameters & Dimensions \\
\hline Ezone (containing two buildings) & $105.15 \mathrm{kWh}$ \\
The peak power of the panels of zone & $77.88 \mathrm{~kW}$ \\
Installed power $(\mathrm{kWp})$ & $79.3 \mathrm{~kW}$ \\
Panel power in STD $(\mathrm{Wc})$ & $305 \mathrm{~W}$ \\
Total number of panels & 260 \\
Number of panels per branch/string & $5 / 52$ \\
Parallel branches (string) & $26 \times 2$ \\
Panel efficiency under STD $(\%)$ & 18.1 \\
The DC/DC converters & $100 \mathrm{~kW}, 300 \mathrm{~V}, 500 \mathrm{~V}$ \\
Energie storage $\mathrm{C}_{\text {nom }}$ & $323538.46 \mathrm{Wh}$ \\
Total number of batteries $(1 \mathrm{KWh}, 12 \mathrm{~V})$ & $336 \mathrm{unités}$ \\
DC bus voltage & $500 \mathrm{~V}$, \\
Total number of series/parallel batteries & $42 / 8$ \\
The DC rated inverter & $100 \mathrm{~kW}, 800 \mathrm{~V}, 210 \mathrm{~A}$ \\
The AC rated inverter & $100 \mathrm{~kW}, 400 \mathrm{~V}, 146 \mathrm{~A}, 50 \mathrm{~Hz}$ \\
Rendement max. & $96,40 \%$ \\
\hline
\end{tabular}

\subsection{Résults of Second phase: verification of the feasibility of the design with the "Homer" design} software

\subsubsection{Global solar energy}

Figure 10 obtained by the Homer software shows the significant influence of the inclination of the panels (40\% additional energy for the unfavorable months). Thus, in spite of the distinctions between seasons, the annual energy produced by the inclined panels remains uniformly distributed. On the contrary, without tilting the overall solar energy is very important, but with an uneven annual distribution.

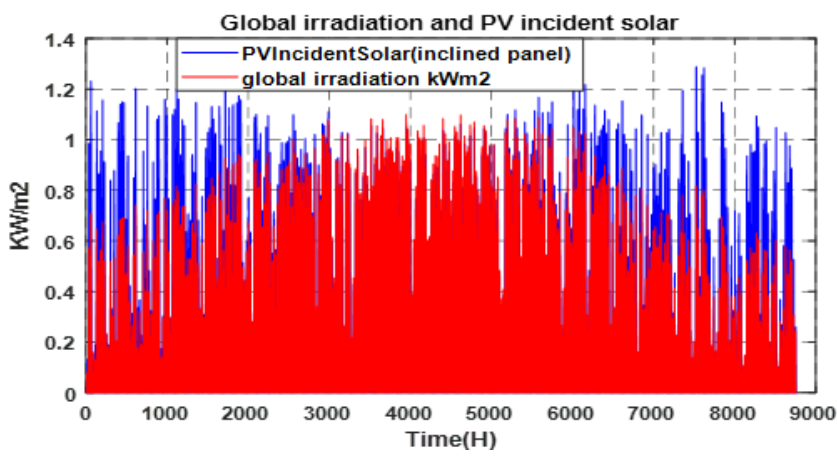

Figure 10. Annual distribution of global solar energy and energy produced by the inclined plane 


\subsubsection{The power flow during the summer and winter}

The comparison of the production of the designed photovoltaic field with the actual consumption of the buildings during the summer solstice (June 21) and the winter solstice (December 21) obtained by Homer in Figure 11 shows that the energy demand is entirely provided by the photovoltaic generators and storage system. It is clear that in the absence of lighting, the load is met by the storage. But from sunrise onwards, the energy flow changes direction. Therefore, during the day, the increasing photovoltaic energy production can only satisfy the demand of the building and the charge of the batteries. Therefore, the company cannot sell excess energy to the power grid until the batteries are fully charged. Figures 11(a) and 11(b) show the electrical power produced by the GPV, the amount of excess electrical power sold to the grid, the charge consumption in $\mathrm{KW}$ and the charge/discharge of the batteries in $\mathrm{KW}$.

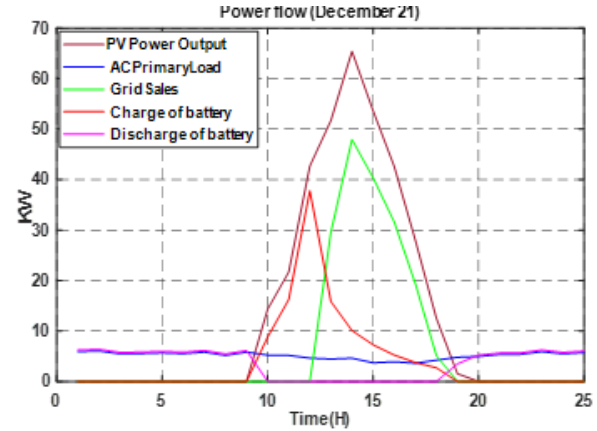

(a)

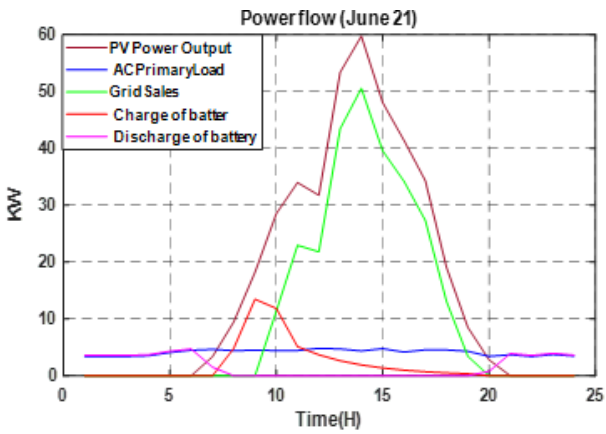

(b)

Figure 11. Electrical power produced by the GPV; (a) The power flow on a winter,

(b) The power flow on a summer

\subsubsection{Energy storage}

The Figures 12(a) and 12(b) show that the availability of energy stored by the battery fully covers the company's consumption during the night and during climatic disturbances. Indeed, this result gives us a good indicator of storage sizing, and it confirms the calculation of the capacity realized in the first phase.

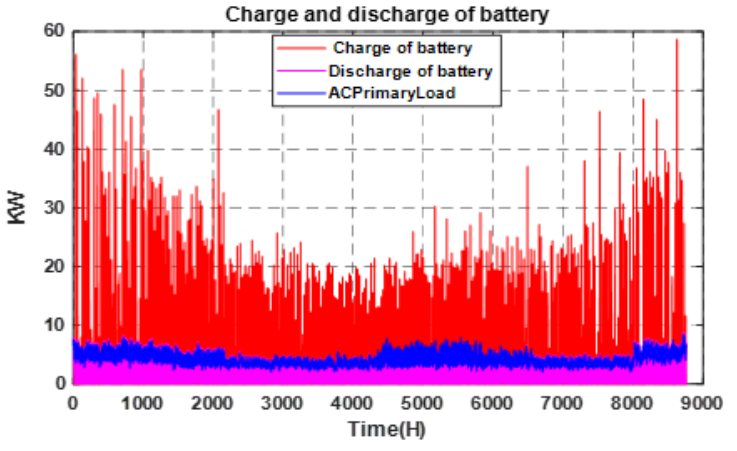

(a)

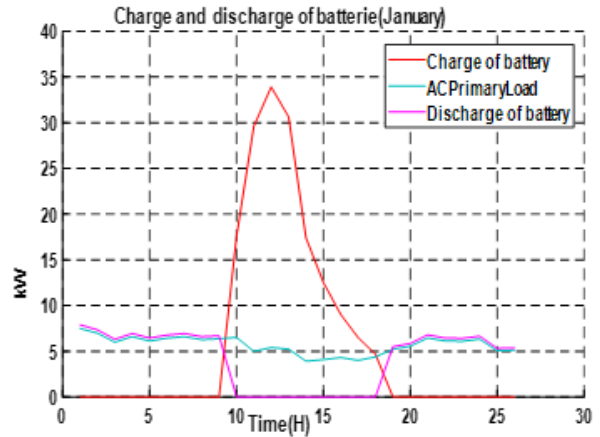

(b)

Figure 12. The charge and discharge of the batteries; (a) The state of charge and discharge of the batteries for one year, (b) The charge and discharge cycle of batteries for one day

\subsubsection{Evaluation}

According to the histogram presented in Figure 11, the breeding center will make an additional profit each month through the sale of excess electricity to the network. We see that the energy injected into the electrical network varies according to the season and weather conditions. Furthermore, it should be noted that the total annual sales made by the company is $6,969 \mathrm{kWh}$, approximately $24.93 \%$ for an annual production of $27,959 \mathrm{kWh}$. The company consumes a total of $20,990 \mathrm{kWh}$ which represents $75.07 \%$. The load profile illustrated in Figures 13(a) and 13(b) correctly reflects the energy consumption of the farm. It is very important during temperate times, due to the air-conditioning of buildings, and it is less important 
during moderate seasons. Indeed, the results of the HOMER software allowed us to validate the sizing steps previously carried out and to have an optimal configuration of the system to ensure the best compromise of technical feasibility and economic profitability. In general, this study highlights the existence of a strong coupling between the components of the photovoltaic system: solar potential, structure, storage, converters, energy management and the load. Therefore, this also justifies a systematic approach to design in which energy optimization of all subsystems is necessary.

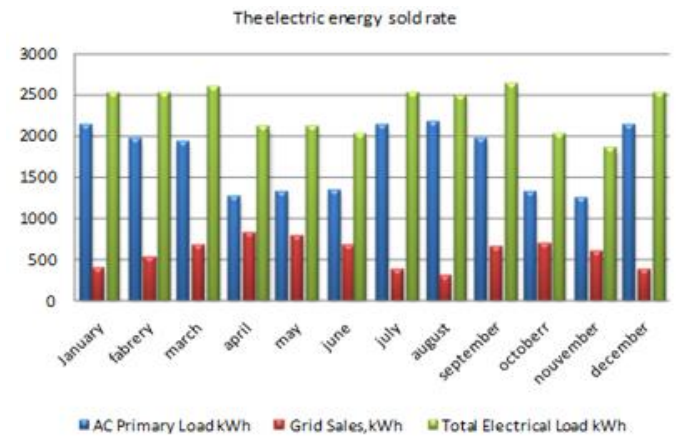

(a)

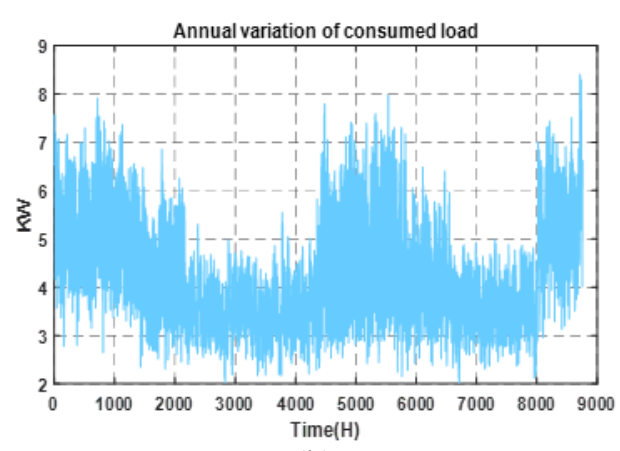

(b)

Figure 13. Evaluation; (a) the energy benefit, (b) annual load

\subsection{Results of the third phase}

\subsubsection{Optimization of the production of GPV by intelligent regulation}

\section{a. MPPT Controller tests}

The graphs in Figure 14 illustrate the input and output signals of the fuzzy controller compared to the conventional $\mathrm{P} \& \mathrm{O}$ controller (disturbance and observation). These graphs show additional gains, power (GPV) and voltage when using the fuzzy controller, especially for transient operation, in constant weather conditions. The results show the effectiveness of the fuzzy controller. It indicates a good indication on the functioning of the designed GPV. Transient response times are very acceptable because the maximum power is reached in $0.1 \mathrm{~s}$. Once again, to validate our method, we tested our controller for different irradiation and temperature values Figure 14(c).

The simulation results obtained in Figure 14(c) show again the efficiency and robustness of the fuzzy controller to extract the maximum power from the photovoltaic generator, whatever the irradiation variations $\left(79.04 \mathrm{~kW}\right.$ for $1000 \mathrm{~W} / \mathrm{m}^{2}$ and $60 \mathrm{~kW}$ for $\left.800 \mathrm{~W} / \mathrm{m}^{2}\right)$. These results are acceptable in terms of system stability. By comparing these results, we can see that the performances of the fuzzy regulation are better than those of the "P\&O" regulation. Therefore, it is proven that the fuzzy controller has better performance, fast response time, very low steady state error and robustness to different variations in atmospheric conditions.

\section{b. Results of Fuzzy charger battery test}

When the irradiation changes, the voltage supplied to the load with the fuzzy controller varies in a range between $503.8 \mathrm{~V}$ and $504.6 \mathrm{~V}$ and reaches a value of 589.5 when the battery operates without regulation as shown in Figure 15. It can be concluded from this result that the influence of the voltage regulator load is maximal because it maintains the voltage in the range that protects the battery.

\section{c. The GPV operating}

On the basis of the results of the two regulators, we performed an analysis of the operation by simulating the voltage and power delivered to the load under constant irradiation and temperature conditions $\left(1000 \mathrm{~W} / \mathrm{m}^{2}, 25^{\circ}\right)$ by the optimized GPV. The purpose of this simulation is to test the robustness of the fuzzy regulators and to ensure the production of the optimal system.

The results shown in Figures 16(a) and 16(b) are very acceptable. In stable mode, the frequency of $50 \mathrm{HZ}$ is respected; the effective amplitude is $380 \mathrm{~V}$ between phases and an effective current of $120 \mathrm{~A}$. The waveforms are perfectly sinusoidal after adjusting the connection filter. The transient active power reaches the value of $170 \mathrm{~kW}$, which is the sum of two powers (PV generator+battery) before the intervention of the battery controller. The same behavior is observed with the effective current value of $260 \mathrm{~A}$. This confirms the efficiency and superiority of the selected fuzzy controller, as well as optimal operation of the GPV. 


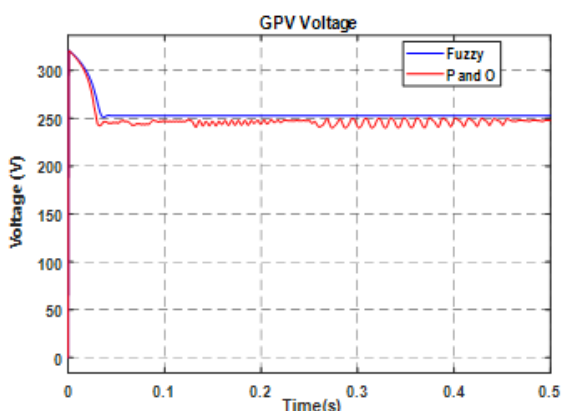

(a)
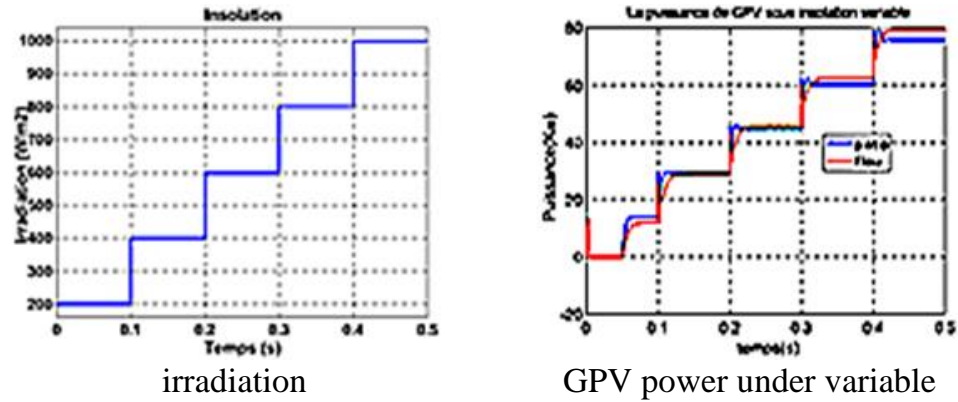
irradiation

(c)

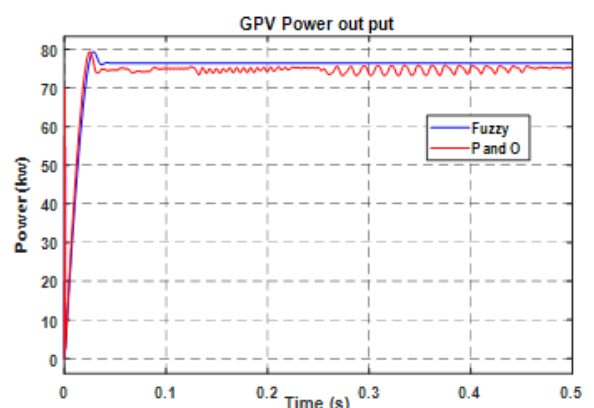

(b)

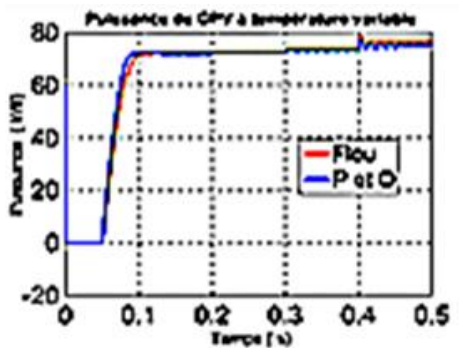

GPV power under variable temperature

Figure 14. MPPT controller tests; (a) GPV voltage fuzzy MPPT and P\&O, (b) the power of GPV Fuzzy MPPT and P\&O, (c) simulation results of (boost) with fuzzy MPPT for different irradiation and temperature values

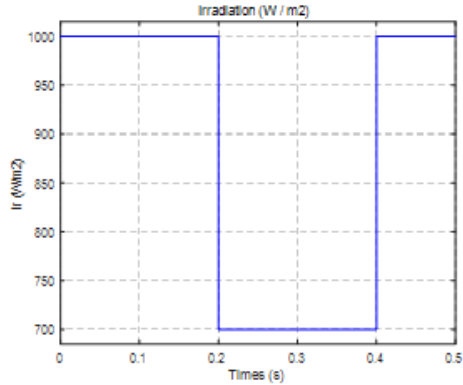

(a)

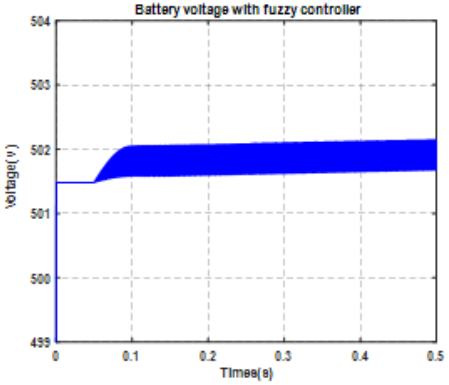

(b)

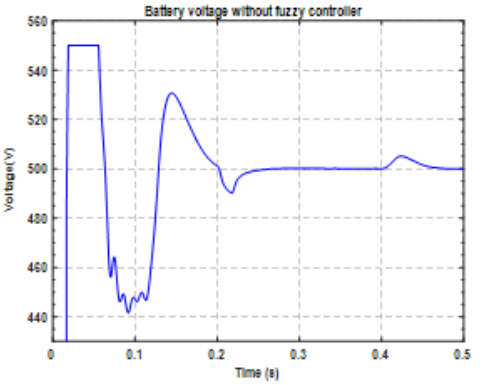

(c)

Figure 15. Simulation results (fuzzy battery charger); (a) irradiation, (b) battery voltage with fuzzy control battery, (c) voltage regulation without control

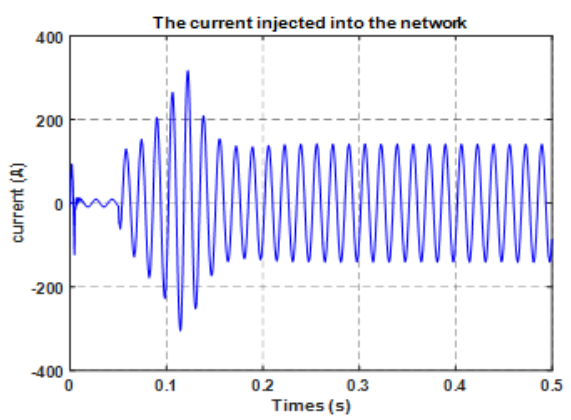

(a)

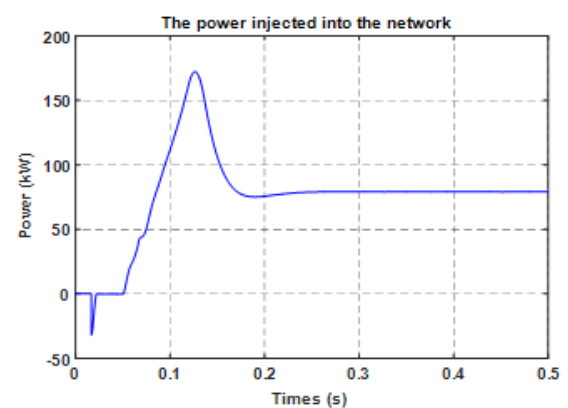

(b)

Figure 16. Simulation results; (a) current at load output, (b) power at load output 


\subsubsection{Results of optimization of electrical energy consumption by intelligent control of the interior climate of the livestock building}

a. External disturbances in temperature and humidity

The Figure 17 shows the curves of two external disturbances in temperature and humidity respectively. These disturbances can be explained by the error between the reference and the controlled temperature value (Tref-Ti) as well as by the humidity curve (Href-Hi). We chose a step of $500 \mathrm{~s}$ $(\approx 9$ minutes), because the temperature and humidity variations $\mathrm{Ti}$ and $\mathrm{Hi}$ are actually quite slow. Thus at $1000 \mathrm{~s}$ for an outdoor temperature and humidity of $19.2{ }^{\circ} \mathrm{C}$ and $77 \%$, the errors with reference to $25^{\circ} \mathrm{C}$ and $60 \%$ are $2.4{ }^{\circ} \mathrm{C}$ for temperature and $5 \%$ for humidity. So, these results show that the internal climate is very well stabilized with the two fuzzy controllers.

b. The temperature and humidity inside the barn

The Figure 18 shows the temperature and humidity results inside the barn. We find that, without a regulator, the response would not only be slow, but also too high, which would have a harmful effect on the hens (health and nutrition), consequently on the weight of the eggs and on the yield of the laying in general. Regarding the two parameters, the effect of our regulator is fairly rapid and responds correctly to the set point. Finally, we deduced by these two tests shown in Figure 17 and Figure 18 that these regulators significantly improve the system by reducing the equipment operating time. Consequently, we have noticed a remarkable optimization of the energy consumed by the building.

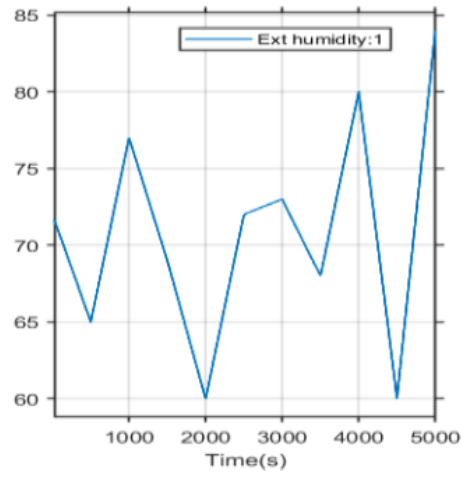

External humidity

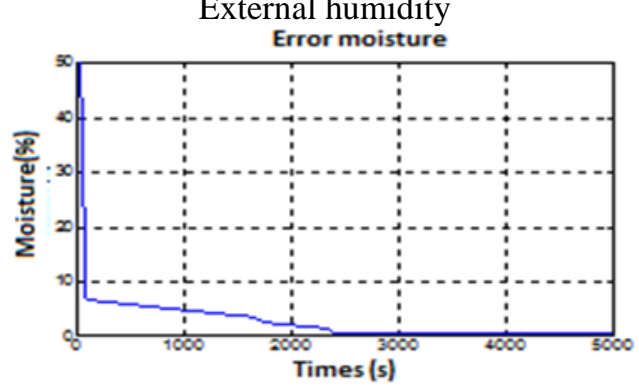

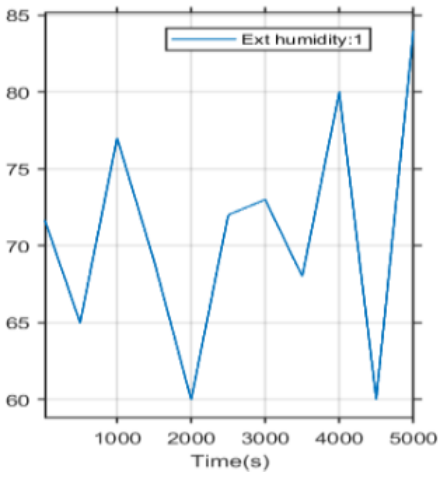

External temperature

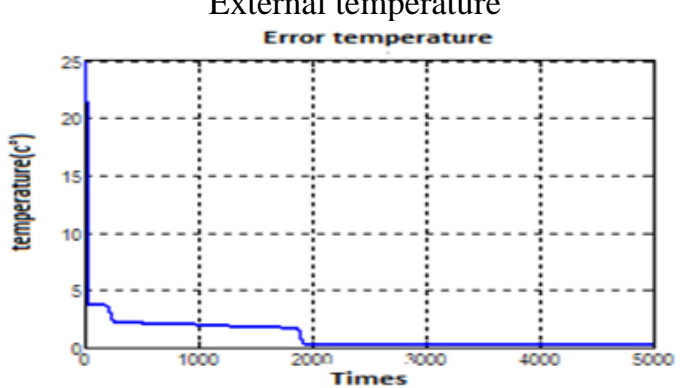

Figure 17. Inputs of the fuzzy controllers
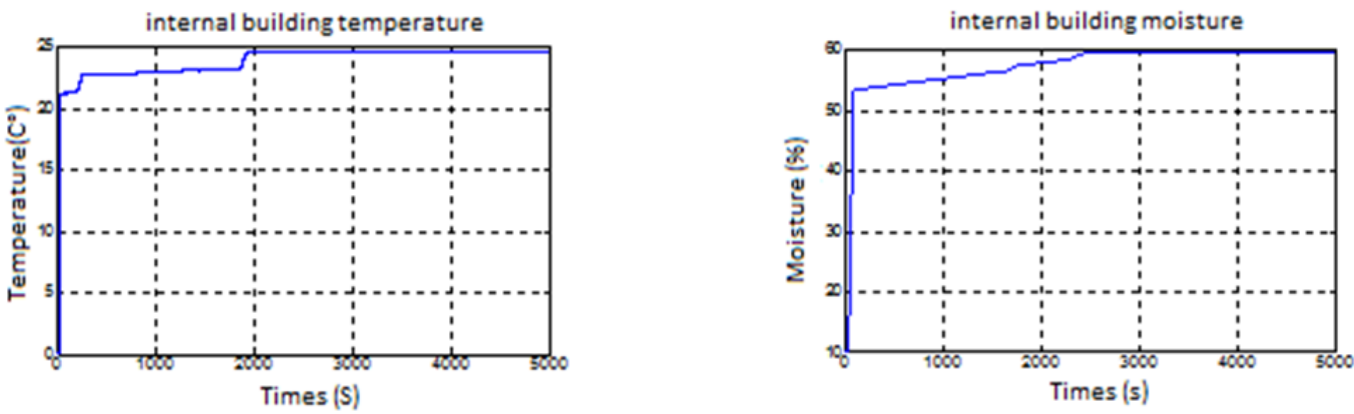

Figure 18. Internal temperature and humidity (controlled) 


\section{CONCLUSION}

In this work, we presented a methodology for the design of an intelligent photovoltaic power plant connected to the grid with storage to feed a chicken breeding company. This approach facilitates the integration of renewable energies in agriculture and reduces the consumption of fossil fuels. These photovoltaic systems make a significant contribution to relieving the burden on the national electricity grid and provide a better service to farmers. In addition to helping to reduce the effects of carbon dioxide, the intelligent power plant also improves the quality of service (no disruption to the power grid). It will benefit from $24.93 \%$ of the sale of surplus energy to the national grid. This is mainly due to the optimization of energy production and consumption by fuzzy controllers.

\section{REFERENCES}

[1] Z. Arthouros, "Report on the Global Status of Renewable Energy 2016," (in French). [Online]. Available: https://www.ren21.net/wp-content/uploads/2019/05/REN21_GSR2016_KeyFindings_fr_09.pdf

[2] C. Chaulet, "A strategic choice, the choice of agronomic technologies: Example of animal production," (in French), The notebooks of the CREAD, vol. 1, no. 7, pp. 115-172, 1986. [Online]. Available: https://www.asjp.cerist.dz/en/article/22270

[3] A. Maheri, "A critical evaluation of deterministic methods in size optimisation of reliable and cost effective standalone Hybrid renewable energy systems," Reliability Engineering \& System Safety, vol. 130. pp. 159-174, 2014, doi: 10.1016/j.ress.2014.05.008.

[4] S. Jorge and D. Vilar, "General introduction to the HOMER software for the design of renewable energy projects", (in French), CEREEC Achada Santo Antonio B.P. 288, Praia, June 2013. [Online]. Available: http://www.ecreee.org/sites/default/files/event-att/02_simulation.pdf

[5] Y. E. A. Eldahab, N. H. Saad, and A. Zekry, "Enhancing the tracking techniques for the global maximum power point under partial shading conditions,"Renewable and Sustainable Energy Reviews, vol. 73, pp.1173-1183, 2017, doi: 10.1016/j.rser.2017.02.029.

[6] N. Bouzidi et al., "Salmonella contamination of laying-hen flocks in two regions of Algeria," Food Research International, vol. 45, no. 2, pp. 897-904, 2012.

[7] Y. Kasmi, "Influence of the breeding mode of laying hens on the quality of eggs," (in French), memory of magister supported in 2016/2017, Institute of Veterinary Sciences and Agricultural Sciences University Batna 1. [Online]. Available: http://theses.univ-batna.dz > doc_download

[8] Mathworks, "Simscape Power Systems Reference (Simscape Components)," 2016. [Online]. Available: http://www.mathworks .com/help/releases/R2016a/pdf doc/physmod/sps/sps ref.pdf

[9] Ministry of energy and mines, "National New and Renewable Energy Program adopted by the Government," (in French), in Feb. 2015 and revised in May 2019. [Online]. Available: https://www.energy.gov.dz/

[10] B. Hotz-Har, "PV Power Plants Sizing and Project Implementation Guide for Engineering Offices," (in French), PACER, 1996.

[11] D. Abbes, "Contribution to the sizing and optimization of wind-photovoltaic hybrid systems with batteries for autonomous residential housing," (in French), Electrical engineering thesis. Poitiers: University of Poitiers, 2012. [Online]. Available: http://theses.univ-poitiers.fr

[12] “Power Data Access Viewer,”NASA. [Online]. Available: https://power.larc.nasa.gov/data-access-viewer/

[13] M. Q. Taha, "Advantages and recent advances of smart energy grid," Bulletin of Electrical Engineering and Informatics (BEEI), vol. 9, no. 5, pp. 1739-1746, Oct. 2020, doi: 10.11591/eei.v9i5.2358.

[14] L. Bridier, "Modeling and optimization of a storage system coupled with intermittent renewable electricity production," (in French), Electrical energy, University of Reunion Island, French, 2016.

[15] M. A. Hamouda et al., "Study and Realization of an intelligent system of electrical energy supply of a house in an urban environment with injection in the network," (in French), Review of renewable energies, vol. 14 no. 2, pp. $187-202,2011$.

[16] N. A.Qarabsh, S. S. Sabry, and H. A. Qarabash, "Smart grid in the context of industry 4.0: an overview of communications technologies and challenges," Indonesian Journal of Electrical Engineering and Computer Science (IJEECS), vol. 18, no. 2, pp. 656-665, 2020, doi: 10.11591/ijeecs.v18.i2.pp656-665.

[17] A. Kaabeche and R. Ibtiouen, "Techno-economic optimization of hybrid photovoltaic/wind/diesel/battery generation in a stand-alone power system," Solar Energy, vol. 103, pp. 171-182, 2014, doi: 10.1016/j.solener.2014.02.017.

[18] N. Agarwal, A. Kumar, and Varun, "Optimization of grid independent hybrid PV-diesel-battery system for power generation in remote villages of Uttar Pradesh, India," Energy for Sustainable Development, vol. 17, no. 3, pp. 210-219, 2013, doi: 10.1016/j.esd.2013.02.002.

[19] A. Bajpai and V.S. Kushwah, "Importance of Fuzzy Logic and Application Areas in Engineering," International Journal of Recent Technology and Engineering, vol. 7, no. 6, pp. 1467-1471, Mar. 2019.

[20] A. Ziouh and A. Abbou, "Fuzzy-Super Twisting Sliding Mode MPPT Control for Three-Phase Grid-Connected PV," International Journal of Renewable Energy Research (IJRER), vol. 8, no. 4, pp. 1812-1823, 2018.

[21] Z. Assia and C. Rachid, "Study of the influence of different parameters on a photovoltaic module," (in French), University Constantine 1 Algeria, 2015 Sciences \& Technology A, no. 41, pp. 49-54, Jun. 2015. 
[22] M. Azzouzi, "Comparaison between MPPT P\&O and MPPT Fuzzy Controls in Optimizing the Photovoltaic Generator," International Journal of Advanced Computer Science and Applications, vol. 3, no. 12, 2012, doi: 10.14569/IJACSA.2012.031208.

[23] P. Takun, S. Kaitwanidvilai, and C. Jettanasen, "Maximum Power Point Tracking using Fuzzy Logic Control for Photovoltaic Systems," Proceedings of the International Multi Conference of Engineers and Computer Scientists, Hong Kong, vol. 2, 2011.

[24] Slamet, E. Rijanto, A. Nugroho, and R. A. Ghani, "A robust maximum power point tracking control for PV panel using adaptive PI controller based on fuzzy logic," TELKOMNIKA Telecommunication, Computing, Electronics and Control, vol. 18, no. 6, pp. 2999-3010, Dec. 2020, doi: 10.12928/telkomnika.v18i6.17271.

[25] E. M. Laadissi, J. Khalfi, F. Belhora, C. Ennawaoui, and A. E. Ballouti, "Aging study of a lead-acid storage bank in a multi-source hybrid system," Indonesian Journal of Electrical Engineering and Computer Science, vol. 20, no. 3, pp. 1109-1117, Dec. 2020, doi: 10.11591/ijeecs.v20.i3.pp1109-1117.

[26] A. Khamis, M. R. Ab. Ghani, G. C. Kim, M. S. M. Aras, M. A. Bin Zabide, and T. Sutikno, "Control Strategy for Distributed Integration of Photovoltaic and Battery Energy Storage System in Micro-grids," TELKOMNIKA Telecommunication, Computing, Electronics and Control, vol. 16, no. 5, pp. 2415-2427, Oct. 2018, doi: 10.12928/telkomnika.v16i5.10249.

[27] L.Wang and H. Zhang, "An adaptive fuzzy hierarchical control for maintaining solar greenhouse temperature," Computers and Electronics in Agriculture, vol. 155, pp. 251-256, Dec. 2018, doi: 10.1016/j.compag.2018.10.023.

[28] C.Wang, W. Cao, B. Li, Z. Shi, and A. Geng, "A fuzzy mathematical method to evaluate the suitability of an evaporative pad cooling system for poultry houses in China," Biosystems Engineering, vol. 101, no. 3, pp. 370-375, Nov. 2008, doi: 10.1016/j.biosystemseng.2008.08.005.

\section{BIOGRAPHIES OF AUTHORS}
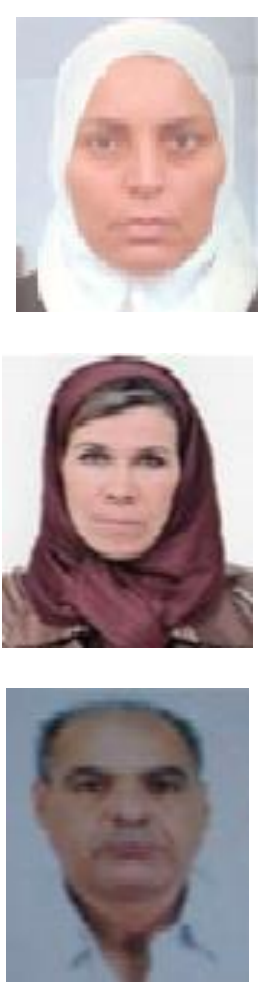

Boutlilis Fatima, Ph.D. teacher-researcher at the Department of Electrical Engineering of Abd el Hamid ibn Badiss University in Mostaganem, Algeria, in renewable energies. His current research focuses on methods for dimensioning photovoltaic generators. We include the comparison of different classical and intelligent controls and their simulations. The objective is to realize an intelligent photovoltaic power plant to supply the farms and reduce pollution from the sector.

Chouitek Mama, $\mathrm{PhD}$ in electrical engineering option: electrical command, teacher-researcher at the Institute of Maintenance and Industrial Safety of the University Ahmed Benhmed Oran 2 Algeria. Her current research focuses on the comparison of different classical and intelligent controls and their simulations in order to be able to build a test bench of the best order for this variable reluctance machine $(6 / 8)$

Bekkouche Benaissa works at the Department of Electrical Engineering of Abd el Hamid ibn Badiss University in Mostaganem, Algeria, as a research professor. Research field: responsible for the doctoral training in methodology for the design of renewable energy sources and the dimensioning of electrical systems. 